\title{
A ARQUITETURA POR UM VIÉS BIOCLIMÁTICO: ESTUDO DE CASO NA ESCOLA GENÉSIO ARAÚJO
}

\author{
ARCHITECTURE FOR A BIOCLIMATE ROAD: CASE STUDY IN THE \\ GENESI ARAÚJO SCHOOL
}

\author{
Fernanda Raniely Araujo Ferreira ${ }^{1}$ \\ Ezio Luiz Martins Simões ${ }^{2}$ \\ Melina Cavalcanti de Melo Bichino ${ }^{3}$ \\ Camilla Furtado de Figueiredo ${ }^{4}$ \\ Rafael Costa de Carvalho Abrantes ${ }^{5}$ \\ Elysson Marcks Gonçalves Andrade ${ }^{6}$
}

RESUMO: Objeivo: Adaptar a Escola Genésio Araújo ao clima quente e seco, por meio de uma intervenção física. Método: Trata-se de um estudoexploratório, com análise qualitativa. Para a avaliação se fez fundamental o conhecimento de referências projetuais e teóricas no mesmo contexto do objeto de estudo, também sendo importante seu levantamento físico e fotográfico, para virtualização no software Revit. Resultados: Foi comprovada a necessidade de readequação da escola, já que algumas salas recebiam a incidência solar direta, tornando esses ambientes desconfortáveis, e podendo acarretar em deficiências no sistema de ensino-aprendizagem. Tendo em vista este fato, foi proposto soluções de proteções para algumas aberturas da edificação, que por fim poderam ser resolvidos com construção de alpendres e uso de arborização, assim concluindo que a pesquisa cumpre o seu objetivo e além de expandir os conhecimentos sobre essa temática. A Arquitetura Bioclimática tem como concepção englobar os princípios associados à diminuição dos impactos ambientais, conservação energética e obtenção de conforto ambiental, que estão diretamente relacionados ao clima, ao poder socioeconômico e político em que a edificação está inserida, a exemplo temos a Escola Estadual de Ensino Fundamental Genésio Araújo, pertencente ao muncípio de São José da Lagoa Tapada, Sertão Paraibano, no qual o clima é quente e seco. Por se tratar de uma edificação pública, nem sempre há o uso de condicionamento artificial, ou seja, não se utiliza de ar-condicionado, no entanto, existem várias técnicas passivas de

\footnotetext{
${ }^{1}$ Graduada em Arquitetura e Urbanismo pela Faculdade Santa Maria, Cajazeiras, Paraíba.

2 Docente da Faculdade Santa Maria, Cajazeiras, Paraíba.

${ }^{3}$ Docente da Faculdade Santa Maria, Cajazeiras, Paraíba.

4 Docente da Faculdade Santa Maria, Cajazeiras, Paraíba.

5 Docente da Faculdade Santa Maria, Cajazeiras, Paraíba.

${ }^{6}$ Docente da Faculdade Santa Maria, Cajazeiras, Paraíba.
} 
condicionamento ambiental que podem ser empregadas no intuito de alcançar à evolução nas condições térmicas das construções. Partindo dessa premissa, se fez importante discutir a influência do conforto térmico, com ênfase na insolação, analisando os impactos causados na edificação e como isso afeta os seus usuários. Conclusão: É de grande relevância o desenvolvimento deste trabalho, a fim de encontrar soluções eficientes que levem em consideração características bioclimáticas.

DESCRITORES: Arquitetura Bioclimática. Arquitetura Escolar. Conforto Ambiental. Condicionamento Ambiental. Incidência Solar.

ABSTRACT: Objective: To adapt the Genésio Araújo School to the hot and dry climate through physical intervention. Method: This is an exploratory study with qualitative analysis. For the evaluation, the knowledge of design was essential, as well as theoretical references in the same context of the study object, also being important their physical and photographic survey, for virtualization in Revit software. Results: The need for readjustment of the school was proved, since some classrooms received direct solar incidence, making these environments uncomfortable, which could lead to deficiencies in the teaching-learning system. In view of this fact, protection solutions have been proposed for some building openings, which can ultimately be solved with the construction of porches and the use of trees, thus concluding that the research fulfills its objective and further expands the knowledge about this thematic. The Bioclimatic Architecture is designed to encompass the principles associated with the reduction of environmental impacts, energy conservation and obtaining environmental comfort, which are directly related to the climate, the socioeconomic and political power which involve the building, such as the State Elementary School Genésio Araújo, in the São José da Lagoa Tapada municipality, Sertão Paraibano, whose climate is hot and dry. Since it is a public building, there is not always the use of artificial conditioning, i.e., no air conditioning is used, however, there are several passive techniques of environmental conditioning that can be employed in order to achieve evolution in the thermal conditions. From this premise, it was important to discuss the influence of thermal comfort, with emphasis on sunshine, analyzing the impacts caused on the building, and how they affect its users. Conclusion: The development of this work is of great relevance in order to find efficient solutions that take into consideration bioclimatic characteristics.

DESCRIPTORS: Bioclimatic Architecture. Environmental Comfort. Environmental Conditioning. Solar Incidence. School Architecture. 


\section{INTRODUÇÃO}

A Arquitetura Bioclimática tem como concepção englobar os princípios associados à diminuição dos impactos ambientais, conservação energética e obtenção de conforto ambiental, nessa arquitetura é o próprio espaço construído que administra suas variáveis do espaço por meio do seu envólucro (paredes, pisos, cobertura), seu entorno (vegetação) e, até dos elementos climatológicos para melhoramento do controle da ventilação e insolação (ROMERO, 2000).

Segundo Vitrúvio (2007), as predisposições das edificações devem ser consideradas conforme as características regionais e variáveis do clima. Com o aparecimento e evolução de equipamentos artificiais, tais como de refrigeração e aquecimento e uma variação de lâmpadas, o arquiteto viu-se livre dos elementos da natureza e do cumprimento às circunstâncias do meio ambiente. (BATISTA, 2004).

As mudanças técnicas trouxeram consigo mudanças culturais. A dissipação do - estilo internacionalll na década de 70 colaborou para a homogeneização da arquitetura em várias partes do mundo (LAMBERTS et al. 1997).

Os novos edifícios passam a ser tratados como objetos dentro dos quais se deve criar, artificialmente, uma temperatura agradável e predomina a concepção projetual centrada no edifício enquanto objeto estético, desprovido de contexto histórico, que prioriza os esquemas gráficos determinados pelo zoneamento de usos e pela função (RHEINGANTZ, 2011, p.40).

No entanto, existe um amplo repertório de técnicas passivas de condicionamento ambientais usadas para se atingir à evolução nas condições térmicas das construções: ventilação natural, resfriamento evaporativo, resfriamento radiante, etc (GIVONI, 1997). Tais técnicas visam a adaptação climática da edificação por entre a escolha segura dos materiais construtivos conforme suas 
especificidades térmicas, ensombramento das aberturas, cor e direção das superfícies externas, relacionados ao uso de fontes naturais de energia para estimular a queda das temperaturas internas (GIVONI, 1994).

Com o intuito de que a edificação tenha um bom desempenho ambiental e energético, compete ao arquiteto atender a relação entre o saber técnico e as medidas práticas que serão passadas ao projeto (AROZTEGUI, 1991). O estudo sobre as necessidades do usuário e sua atuação no decorrer do tempo de uso da edificação ainda consiste em um informe válido, pois possibilita constatar fatores culturais e socioeconômicos que podem interceder na competência dos pontos de condicionamento ambiental pensados pelo arquiteto. Tendo em conta todos esses conhecimentos ao longo da fase de projeto, a obra finalizada caracteriza-se- á como uma soma de soluções ajustadas entre si e integradas ao meio. (PEREIRA; NETO, 1988).

O conforto ambiental é uma das questões mais relevantes quando se fala em harmonia no ambiente construído, o que pode ser alcançado atendendo as normas pertinentes, que apresentam soluções projetuais, tendo em vista o clima, entorno e os materiais utilizados (COBERLLA; YANNAS, 2003).

No caso específico de edificações escolares, a adaptação ambiental é de suma importância, posto que o sistema de ensino-aprendizado flui com mais facilidade em espaços térmicos e acusticamente confortáveis.

O ambiente escolar deve ser projetado para garantir o máximo de conforto com relação à temperatura, vento, umidade, proporcionar condições ideais de visão e iluminação natural ou artificial, qualidade acústica por meio de materiais isolantes que protejam de ruídos externos, para garantir estabilidade estrutural da edificação, salubridade e higiene, segurança, entre outros (VISENTIM; CARDOSO; BENINCÁ, 2017, p. 51).

Segundo Kowaltowski (2011), a concepção arquitetônica dos prédios escolares obedece à situação socioeconômica e política do município em que está inserida, mas nem sempre atente aos conceitos de conforto, fundamentais para alcançar uma qualidade no sistema de aprendizagem. É notório que a preocupação 
principal nas construções escolares públicas é atender a demanda de alunos, pouca se atenta à qualidade das edificações e como tal vai influenciar na formação do estudante.

Partindo dessa premissa, se faz importante discutir a influência do conforto térmico, com ênfase na insolação, analisando os impactos causados na edificação e como isso afeta os seus usuários.

Neste contexto, a presente pesquisa tem como objetivo uma intervenção, através da análise de uma edificação escolar, localizada na zona urbana da cidade de São José da Lagoa Tapada-PB, para adaptá-la ao clima local, o quente e seco.

\section{MÉTODO}

O presente trabalho constitui em busca aplicada, de caráter exploratório, no qual o estudo se encontra na fase inicial, e assim propõe não só associar os aspectos de análise, como também de definição dos objetivos e formulação das hipóteses. Do mesmo modo de natureza descritiva, em que se registra e observa a fim de transcrever os fatos (PRODANO; FREITAS, 2013).

Posto isto, os resultados serão retratados sobre forma quantitativa, com base em coleta de dados, e em seguida, analisá-las qualitativamente. Quanto ao método, compreende-se como hipotético-dedutivo, partindo de uma problemática, para apresentação de uma hipótese e esta será verificada e solucionada (POPPER, 1972).

A aplicação do método apresentado engloba os seguites pontos:

A) Referência Projetual: Compõe-se na pesquisa de correlatos que venham a conter diretrizes projetuais com soluções à incidência solar, assim direcionando o resultado final deste estudo;

B) Revisão Bibliográfica: Constitui-se na pesquisa em material publicado, como livros e artigos científicos, sobre conforto térmico e ambiente escolar;

C) Coleta de dados e pesquisa in loco: Visita à escola, para realização do levantamento físico e fotográfico; 
D) Virtualização: Após o passo anterior, será efetuada sua virtualização no software Revit;

E) Análise Geral: Em seguida, foi feita a análise da situação atual da escola, a fim de apontar como se comporta a incidência solar na edificação durante o ano;

F) Projeto de intervenção: Ao identificar problemas na edificação, foi feito um projeto de intervenção para adaptação da escola ao clima quente e seco.

O fluxograma abaixo ilustra o método utilizado:

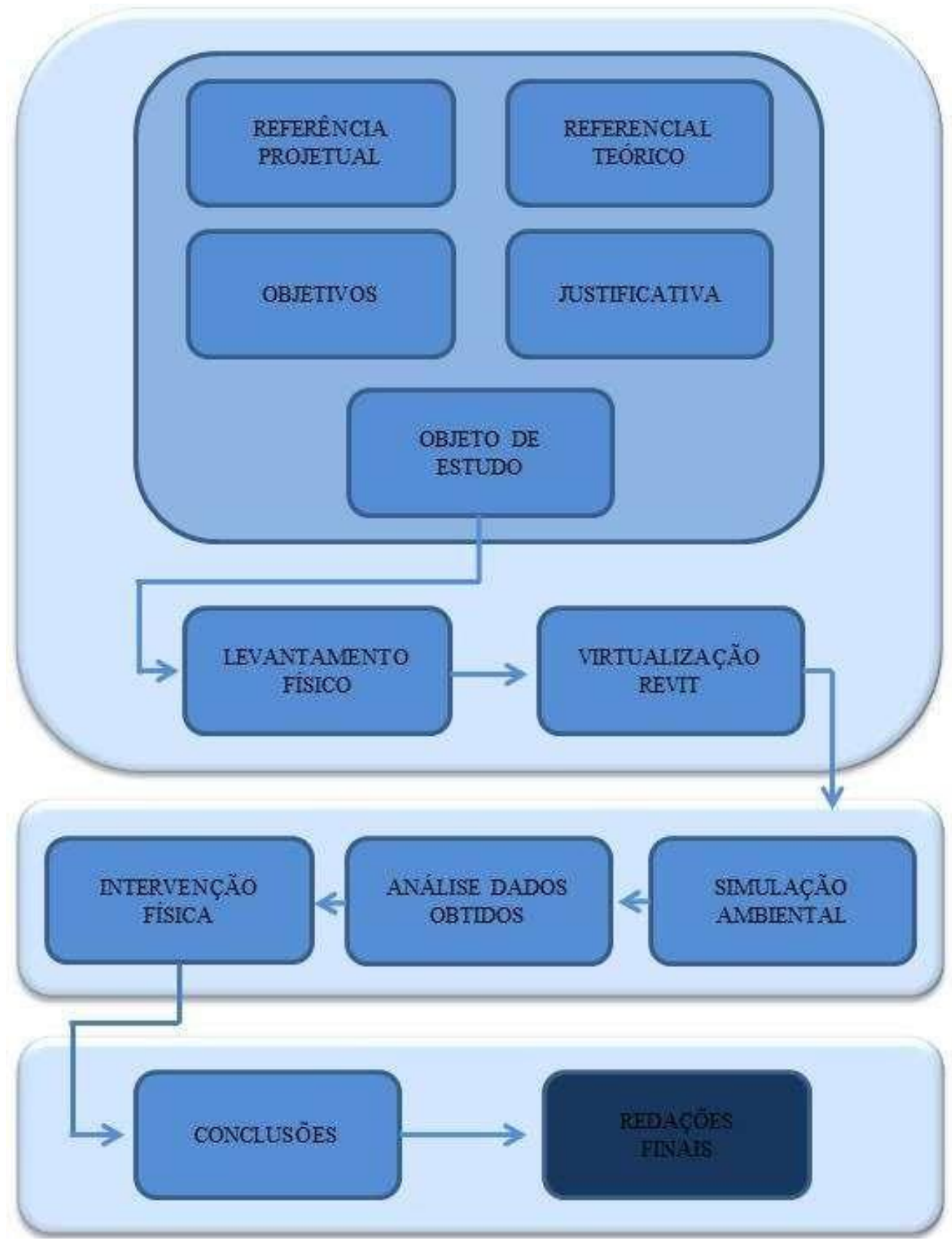

Fonte: Elaborado pelor autor, 2019. 
Dois projetos foram escolhidos para 0 embasamento da análise $\mathrm{e}$ posteriormente e o anteprojeto de adaptação de uma edificação escolar ao clima quente e seco. $O$ critério da escolha deu-se através de projetos que apresentam soluções para o conforto térmico, dando ênfase ao uso de proteções para incidência solar.

Para a análise foi utilizado o Método de Baker, o qual leva em consideração seis princípios, que são: Genius Loci (contexto), Iconologia, Identidade, Significado do Uso, O Movimento e a Geometria (forma), Estrutura e Materiais.

\section{RESULTADOS E DISCUSSÃO}

Após virtualização no software Revit (2017), foi realizado um estudo da insolação e sua incidência na edificação escolar em análise. Os horários observados foram os das 9, 12 e 15 horas nos solstícios (21 de do mês de junho e dezembro) e equinócios (20 de março e 23 de setembro).

Observou-se que durante todo o ano, no horário das $9 \mathrm{~h}$, o leste da edificação fica exposto à incidência solar, como também alguns ambientes da fachada norte, mais especificamente a sala de aula 01, a sala de secretaria, cozinha e banheiro masculino, isso no Equinócio e Solstício de Inverno. 
Figura 1. Análise de Insolação às $9 \mathrm{~h}$

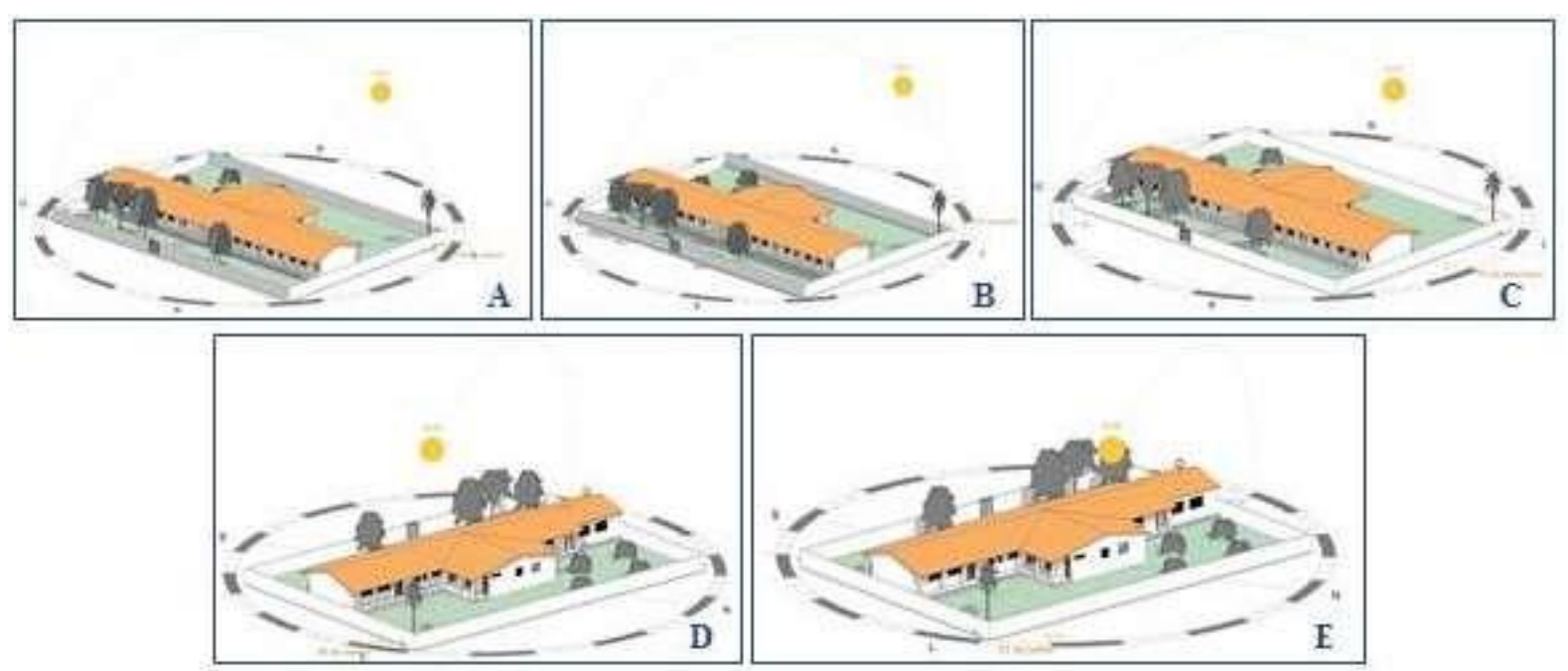

Fonte: Elaborado pelo Autor, 2019.

A incidência solar direta no horário das $12 \mathrm{~h}$ ocorre no Solstício de Verão na sala de aula 01, oeste da edificação. Assim como no Solstício de Inverno na fachada norte, apenas o leste da escola fica protegida pelos alpendres existentes.

Figura 2. Análise de Insolação às $12 \mathrm{~h}$.

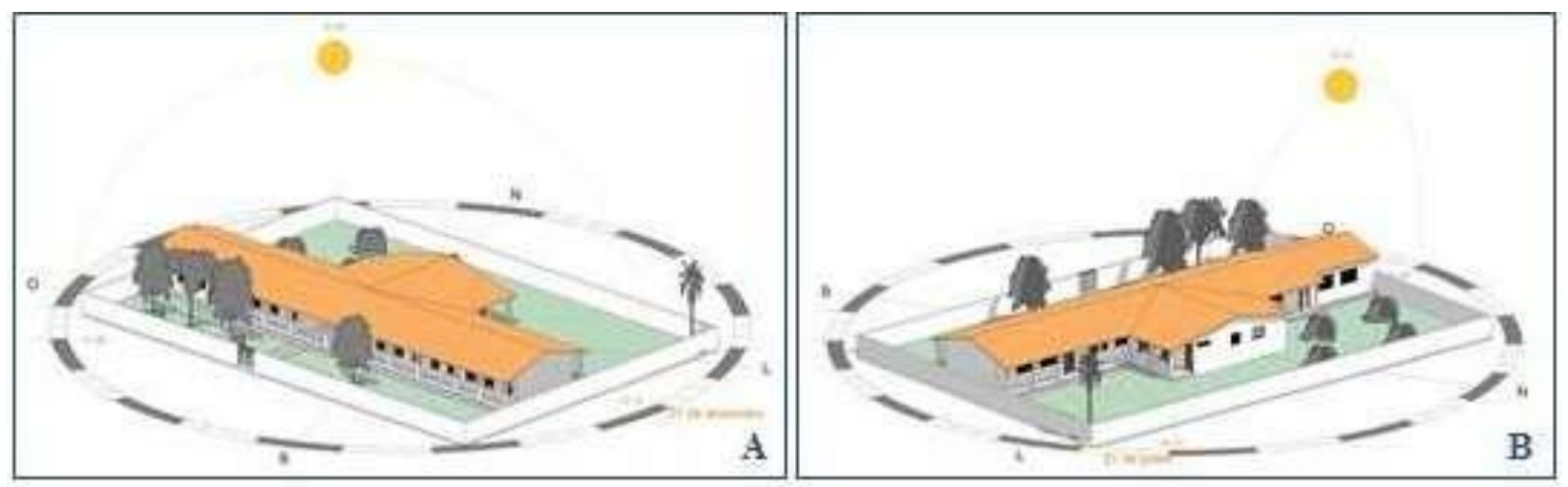

Fonte: Elaborado pelo Autor, 2019.

No oeste da edificação a sala de aula 01 e no Solstício de Verão, a fachada norte estão exposta à incidência solar, mas observa-se que algumas salas estão protegidas pela arborização existente. Já a sala de aula 01, sala de secretaria, 
cozinha e banheiro masculino no Solstício de Inverno, norte, recebem parcialmente luz solar direta. Isto no horário das $15 \mathrm{~h}$.

Figura 3. Análise Insolação às 15h.

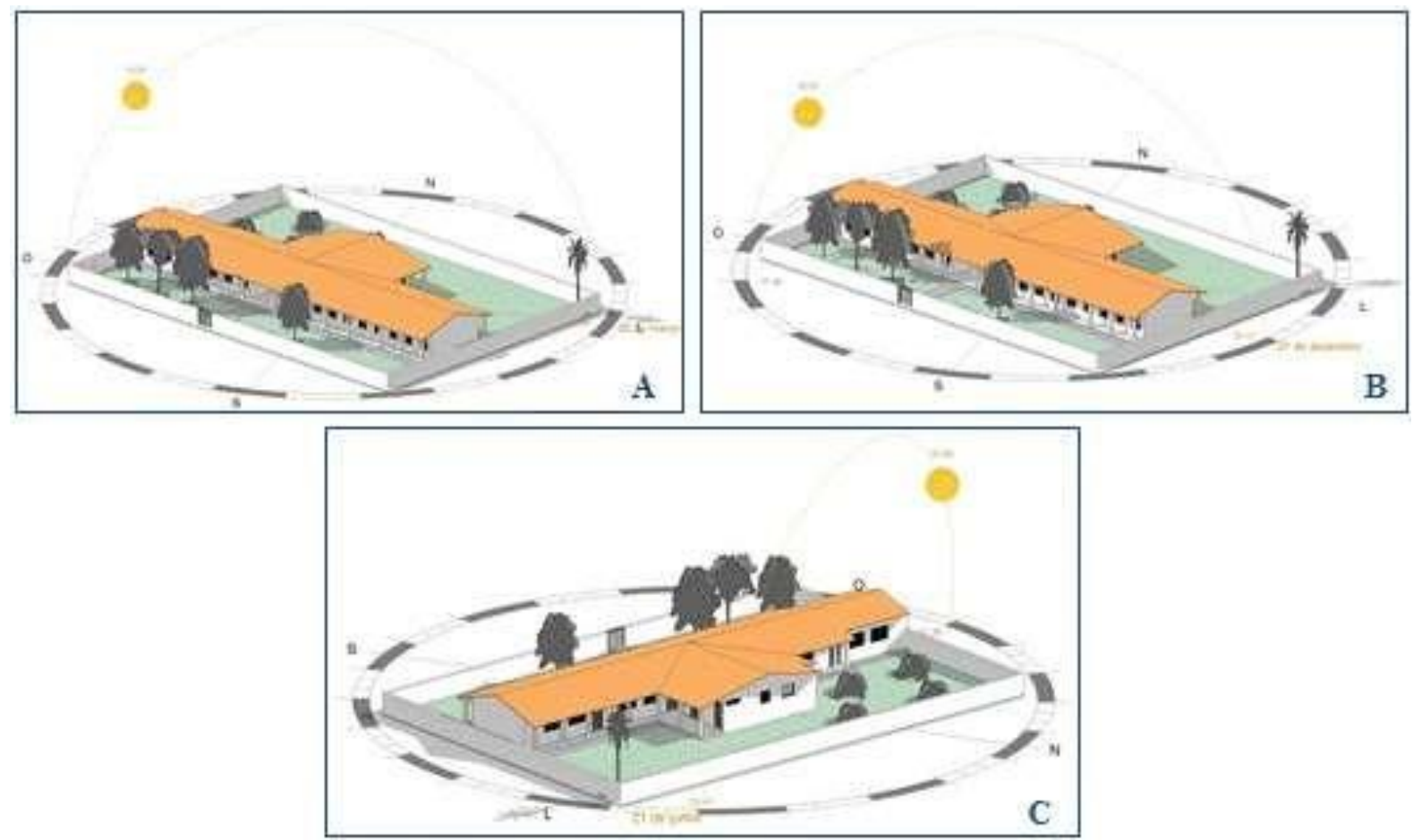

Fonte: Elaborado pelo Autor, 2019.

Após a análise de incidência solar na situação atual da instituição escolar, foram propostas algumas soluções eficientes que cumpre com o objetivo desta pesquisa.

Observou-se que em algumas salas não faz o uso de alpendre, ponto característico da arquitetura da escola, e são estas as que mais sofrem com a insolação. Tendo vem vista, foi sugerida a continuação do alpendre em toda a edificação. Esta solução foi embasada de acordo os dizeres de Romero (2010), que cita:

Nas regiões que possuem grandes diferenças de temperatura entre o dia e a noite e com temperaturas noturnas muito abaixo da faixa de conforto térmico (noites frias), não é interessante a perda rápida, à noite, do calor acumulado durante o dia; podese, portanto, introduzir elementos na edificação, tais como 
varandas, alpendres para que a construção, no seu conjunto, crie, à noite, barreiras contra o esfriamento rápido. Forma-se ao redor dos lugares de permanência da família uma espécie de invólucro protetor. Estes elementos, por outro lado, não devem impedir a penetração solar no período com noites frias (inverno), mas por outro, devem impedir a penetração dos raios solares nos períodos quentes (verão) (ROMERO, 2010, p. 50).

Como também, o projeto correlato visto no capítulo anterior, a Escola Novo Mangue, faz uso de alpendres, mostrando ser uma proposta eficiente e simples. Para proteção de outra área, foi sugerido uso de vegetação, a qual tende diminuir os efeitos do clima, estabelecendo um microclima. Perante o rígido clima do sertão, foi optado por plantas típica da região, sendo a baraúna e o mulungu (ANA, 1998).

\section{CONCLUSÃO}

Conclui-se que esta pesquisa cumpre com o objetivo proposto, que é a análise de uma edificação escolar a fim de adaptá-la ao clima que está inserida, o quente seco, por meio de uma intervenção física, levando em consideração a incidência solar.

Ademais, a pesquisa fortalece a relevância do estudo climático na fase projetual, além de propagar metodologias relacionadas à simulação ambiental. $O$ que também pode ser levado em consideração é a carência de estudos dessa natureza no município, relacionados ao conforto ambiental em instituições escolares.

A composição desta análise vem colaborar para novas pesquisas sobre esse tema, ampliando ainda mais o conhecimento no estudo sobre incidência solar no objeto construído, estimulando novas indagações, e principalmente incitar em outros pesquisadores da construção civil a importância de uma edificação adequada ao seu clima, desde a etapa projetual ou em adequações em construções já existentes. 
Por fim, é de grande relevância o desenvolvimento deste trabalho, a fim de encontrar soluções eficientes que levem em consideração características bioclimáticas.

\section{REFERÊNCIAS BIBLIOGRÁFICAS}

AROZTEGUI, J.M. Sobre la normativa de exigencias mímimas para la construcción de vivendas en los paises del Cono Sur de America. In: I Encontro Nacional de Normatização Ligada ao Uso Racional de Energia e ao Conforto Ambiental em Edificações. Anais... Florianópolis: ANTAC, 1991. p. 10-15. Disponível em: <http://www.infohab.org.br>. Acesso em: 18 outubro 2018.

BATISTA, J. O. 2004. 53 f. Arquitetura bioclimática para o semi-árido alagoano: Centro Comercial e de Serviços em Santana do Ipanema. Trabalho Final de Graduação (Bacharelado em Arquitetura e Urbanismo) - Departamento de Arquitetura e Urbanismo, Centro de Tecnologia, Universidade Federal de Alagoas, Maceió, 2004.

BATISTA, J. O. 2006. A arquitetura e seu desempenho térmico no contexto do semi- árido alagoano: Estudos de caso em Santana do Ipanema - AL. Trabalho de Pós - Graduação em Arquitetura e Urbanismo - Universidade Federal de Santa Catarina, Centro Tecnológico, Santa Catarina, 2006.

BARBOSA, M. J. et al. Aperfeiçoamento e desenvolvimento de novos métodos de avaliação de desempenho para subsidiar a elaboração e revisão de normas técnicas. In: ROMAN, H. R.; BONIN, L.C. (Ed.). Coletânea Habitare, v. 3, Normatização e certificação na construção habitacional. 2003, p. 43-53.

CORBELLA, Oscar; YANNNA, Simas. Em busca de uma arquitetura sustentável [2.ed.]. [S. I.]: Revan, 2011.

Escola Primária em Gando / Kéré Architecture" [Primary School in Gando / Kéré Architecture] 06 Mai 2016. ArchDaily Brasil. (Trad. Martins, Maria Julia) Acessado 15 de Maio 2019. $<$ https://www.archdaily.com.br/br/786882/escola-primaria-em-gando-kere-architecture> ISSN 0719-8906

Escola Novo Mangue / O Norte - Oficina de Criação" 08 Abr 2016. ArchDaily Brasil. Acessado 15 Maio 2019. <https://www.archdaily.com.br/br/785161/escola-novo-mangue-o-norte-niloficina-de-criacao> ISSN 0719-8906.

FANGER, P.O. Thermal comfort. Analysis and applications in environmental engineering. Macgraw-Hill Book Company, 1970.

GARCIA-CHÁVEZ, J. R. The potential of passive cooling strategies for improving ambient comfort conditions and achieving energy savings in a typical hot/arid climate. In: PLEA International Conference, 1999. Anais... p.412-426, 1999.

GIVONI, B. Climate considerations in building and urban design. New York: John Wiley \& Sons Inc., 1997.

GIVONI, B. Passive and low energy cooling of buildings. New York: Van Nostrand Reinhold publishing company, 1994.

HUMPHREYS, M. A. Outdoor temperatures and confort indoors. Garston. Watford. Building 
Research and Practice. v. 6, p. 92-105. Mar/Apr.

INSTITUTO BRASILEIRO DE GEOGRAFIA E ESTATÍSTICA - IBGE. Censo Demográfico. Disponível em :<http://cidades.ibge.gov.br/brasil/pb/sao-jose-da-lagoa - tapada/historico>. Acesso em: 18 de março de 2019.

INSTITUTO NACIONAL DE METEOROLOGIA - INMET. Dados Climatológicos de São Gonçalo-PB. Disponível em <http://www.inmet.gov.br/>. Acesso em 10 de maio de 2019.

KOWALTOWSKI, Doris C. C. K. Arquitetura escolar: o projeto do ambiente de ensino / Doris C. C. K. Kowaltowski. São Paulo: Oficina de Textos, 2011, p. 111-156.

LAMBERTS, R.; DUTRA, L; PEREIRA, F. Eficiência energética na arquitetura. São Paulo: Ed. PW, 1997.

PEREIRA, F. O. R.; NETO, J. A. B. da C. Princípios para otimização do desempenho térmico de componentes da edificação. In: Simpósio de Desempenho de Materiais e Componentes de Construção Civil, 1. Anais... Florianópolis: ANTAC, 1988, p. 124 - 131.

RHEINGANTZ, P. A. Pequena digressão sobre conforto ambiental e qualidade de vida nos centros urbanos. Ciência \& Ambiente: revista da Faculdade de Arquitetura e Urbanismo da UFSM, Santa Maria. vol. 22, jan/jun 2001, p. 35-58.

ROMERO, Marta Adriano B. Princípios Bioclimáticos para o Desenho Urbano. [S. I.]: CopyMarket.com, 2000.

SANTAMOURIS, M; ASIMAKOPOULOS, D. Passive cooling of buildings. James \& James Science Publishers, 1996.

SCHNEIDER, M. Do school facilites affect academic outcomes. National Clearinghouse for Educational Facilities. nov. 2002.

VITRÚVIO, Marcos. Tratado De Arquitetura. Martins Fontes, 2007.

WATSON, D; LABS, K. Climatic Building Design. Energy- eficient building principles and practice. McGraw- Hill book Company. 1983. 